\title{
Grain Refinement and Mechanical Properties of Three 5xxx Aluminum Alloys after Equal Channel Angular Extrusion
}

\author{
S. T. Adedokun
}

Mechanical Engineering Department, FAMU-FSU College of Engineering, Tallahassee, FL 32310, USA

The Equal Channel Angular Extrusion (ECAE) is formed from two channels of equal cross-section, intersecting to form a 'sharp' corner. Deformation occurs at the die corner as the billet is pressed. Effective strain per pass is dependent on the angle of intersection of the die channels and to a lesser extent on the fillet radius at the die corner. ECAE has been used for uniform plastic deformation [1], increase material strength, and produce ultrafine-equiaxed grains (UFG) [2], complex microstructures [3] and powder consolidation or compaction [4].

This present work looks at the changes in the properties of three 5xxx aluminum alloys of similar compositions after ECAE at room temperature for 4 passes. The compositions of the three aluminum alloys are: $5083 \mathrm{H} 116 \mathrm{Al}$ 94.04, Cr 0.113, Cu 0.047, Fe 0.278, Mg 4.465, Mn 0.65; $5086 \mathrm{H} 116 \mathrm{Al}$ 94.80, $\mathrm{Cr}$ 0.124, $\mathrm{Cu}$ 0.038, Fe 0.227, Mg 4.137, Mn 0.437 and $5456 \mathrm{H} 116 \mathrm{Al}$ 93.96, Cr 0.11, Cu $0.10, \mathrm{Fe} 0.17, \mathrm{Mg} 4.85, \mathrm{Mn} 0.65$.

Microstructural properties that have been looked at include grain size, misorientation angle variation and the textural homogeneity/heterogeneity across the three materials. Microhardness and hardness are some of the mechanical properties measured for all the test samples. Equipment used for these measurements include ESEM, OIM, x-ray diffractometer and optical microscope.

Some of the results of this work are still being collated. Figures 1 to 3 represent the inverse pole figures of the surfaces of the as-received materials as determined by an x-ray diffractometer. It could be seen that there is some degree of textural homogeneity across the as-received materials.

References

[1] S. Komura, M. Furukawa, Z. Horita, M. Nemoto and T. G. Langdon, Materials Science and Engineering A297 (2001), 111-118

[2] U. Chakkingal and P. F. Thomson, Journal of Materials Processing Technology, 117 (2001), $169-177$

[3] S. Ferrasse, V. M. segal and F. Alford, Materials Science and Engineering A372 (2004), 44-55

[4] O. N. Senkov, D. B. Miracle, J. M. Scott and S. V. Senkova, Journal of Alloys and Compounds, 365 (2004), 126-133

[5] This work was supported by NSF with Grant No. DMR-0351770 


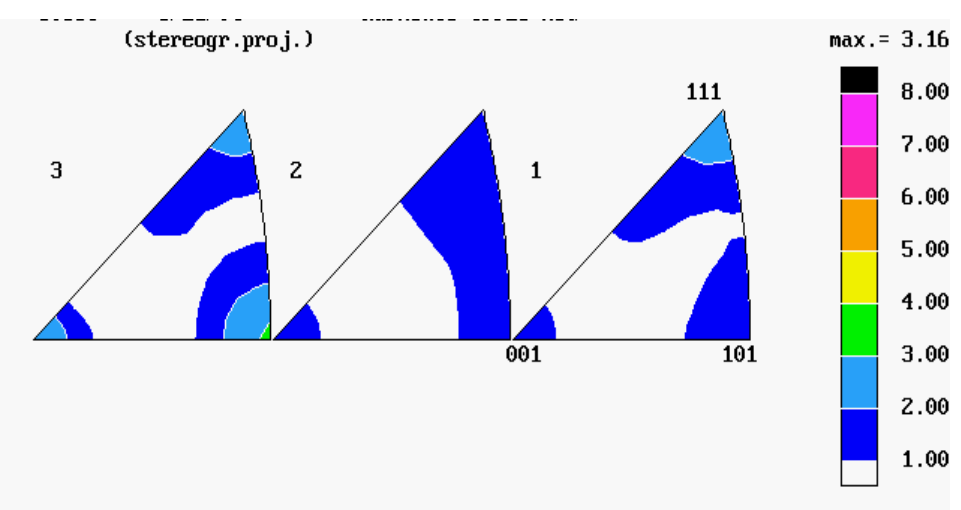

lin. scale

Figure 1. Inverse Pole Figure of the surface of as-received 5083

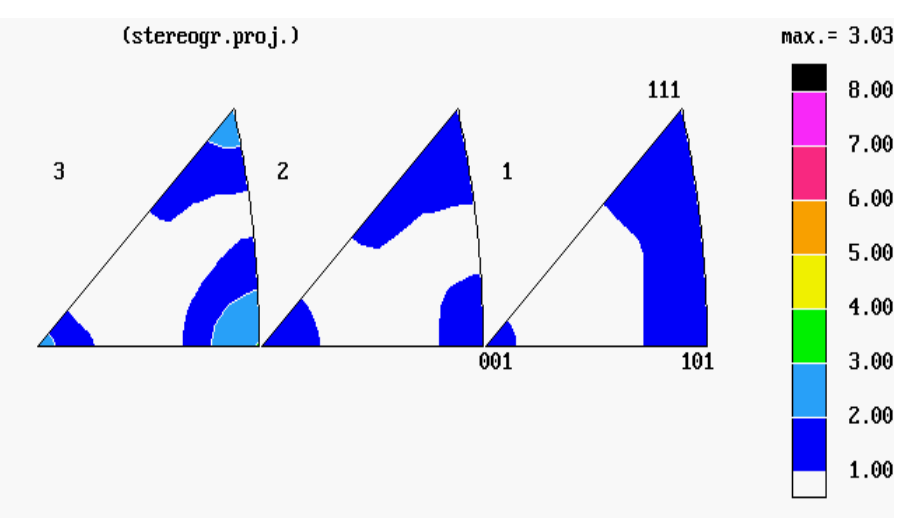

Figure 2. Inverse Pole Figure of the surface of as-received 5086

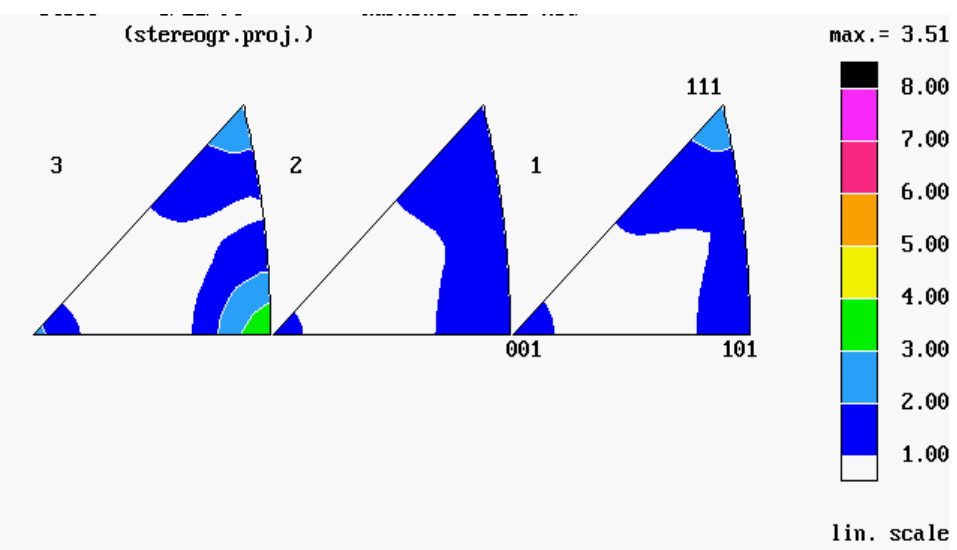

Figure 3. Inverse Pole Figure of the surface of as-received 5456 